\title{
Analysis on the Competitive Procurement Bidding Evaluation Method of Equipment
}

\author{
Yin Ji-wei, Zhang Hua, CHEN Dong-wei \\ Department of Equipment Command and Management, Ordnance Engineering College, Shijiazhuang \\ 050003, China
}

Keywords:Bidding evaluation; Equipment competitive procurement; the fuzzy comprehensive evaluation method

\begin{abstract}
Since the reform and opening, China's market economy develops rapidly. Under the national macroeconomic regulation and control, the market economy make the economic benefits becomes more and more high, but our army's equipment procurement still stays in the planned economy mode. This mode invests a lot of manpower and material resources, but the expected benefits can't be reached so that the equipment procurement of our army can't keep up with the times. In this paper, how to adopt the equipment competitive procurement is analyzed, the fuzzy comprehensive evaluation method of mathematical models is built and the model is used in practical application, the advantages and disadvantages of the method are summarized.
\end{abstract}

\section{Introduction}

In 2005, the Central Military Commission transmitted 《Opinions on deepening the procurement system of equipment $》$ which introduced by the four headquarters, the opinions clearly proposed that the military strategy in the new period should be centralized, the military struggle preparation should be leader and the relevant policies and regulations of the state and army should be the basis, the equipment procurement operation mechanism reform which take competition as core should be promoted ${ }^{[1]}$. In current market economy system, the army has maintained its planned economic system for a long time, which is not conducive to the efficiency and effectiveness of equipment procurement projects. The use of equipment competitive procurement is appeared as a natural form of equipment procurement with the improvement of economy. In order to maximize the benefits and efficiency of the competitive procurement, the equipment procurement should be strictly managed, and a set of optimal bidding system should be implemented.

Bidding is a kind of organized and standardized transaction operation mode. Under normal circumstances, the buyer (tenderee) send notice or invitation to the seller (bidder), called on companies to bid and the each bidder's bid documents were compared, evaluated and analyzed accord to the established evaluation criteria and methods, finally the best seller's bid is selected. The quality of the bid evaluation has a direct impact on the whole bidding process of the military enterprises and the army, and it decides whether the two sides can achieve the maximum benefit and efficiency. Therefore, the core part of the bidding is the evaluation. Combined with some important factors of the competitive procurement of equipment, the method of bidding evaluation is analyzed in this paper. 


\section{Equipment competitive procurement evaluation method}

At present, there are three common methods of bidding evaluation: lowest bidding price method, comprehensive evaluation method and modern comprehensive evaluation method.

2.1.Lowest bidding price method

The lowest bidding price method is an evaluation method which chooses bidder with lowest price as winner on the premise to satisfy the requirements of the bidding documents [2]. The method is generally applicable to some simple equipment, semi-finished products, raw materials and some project which requirements are not very strict. The lowest bidding price method is simple and convenient, but in addition to price the other factors are ignored, the bid price is quoted as the only standard to select the best bid. Obviously this method is not suitable for the procurement of equipment of our army.

2.2 Comprehensive evaluation price method

Comprehensive evaluation price method is an evaluation method which calculate the comprehensive scores of tender documents according to the regulation of various indicators on the premise to satisfy the requirements of the bidding documents, then the scores are accumulated and the highest score is determined as the winner[3]. The mathematical model of comprehensive evaluation method is expressed as follows:

$$
U_{j}=\stackrel{a}{i=1}_{n}^{n} A_{i j}
$$

Where, $\mathrm{U}$ represents the comprehensive score, $\mathrm{A}_{\mathrm{ij}}$ is the $i$-th indicators score of $j$-th tender company, $\mathrm{n}$ is the total number of indicators considered.

Compared with the lowest tender price method, the comprehensive evaluation method has a great improvement. The method takes more attention to the other factors. However, this method does not complete the evaluation rules and the evaluation indicators are not standardized. The subjective factors have a great influence because the comprehensive evaluation method is mainly relied on expert scoring.

Modern comprehensive evaluation price method

In order to make the comprehensive evaluation method more suitable to the best effect of the bidding, the modern comprehensive evaluation price method is also studied. Modern comprehensive evaluation price methods mainly have the following several kinds: AHP (analytic hierarchy process, AHP), artificial neural network (ANN), data envelopment analysis (data envelopment analysis, DEA) fuzzy comprehensive evaluation method, and grey comprehensive evaluation method ${ }^{[4]}$.

Because of the complexity of the competitive procurement in weapons and equipment, the fuzzy comprehensive evaluation method is used to carry out the application of competitive purchasing.

\section{Model and steps of fuzzy comprehensive evaluation method}

\subsection{Factor set of evaluation object}

The evaluation index system and evaluation grade are determined by evaluation team composed of the tendree, $\mathrm{U}=\left\{\mathrm{u}_{1}, \mathrm{u}_{2}, \cdots, \mathrm{u}_{\mathrm{m}}\right\}$ is set as the $\mathrm{m}$ kind of evaluation indicators. In the formula, $\mathrm{m}$ is the number of evaluation indicators, and it is determined by a specific set of indicators. 
In order to make the weight distribution more appropriate and convenience, according to the evaluation index of the functional areas, the evaluation index are divided into several classes, The first grade indexes is independent and does not affect the other evaluation index. Using this method, the first grade index can be divided into the second index, each index has its importance and they are not interfered and influenced by each other. This method can be drawn:

$$
U=U_{1} \text { 热 } U_{2} \cdots ? U_{S}
$$

Where $\mathrm{U}_{\mathrm{i}}=\left\{\mathrm{u}_{\mathrm{i} 1}, \mathrm{u}_{\mathrm{i} 2}, \cdots, \mathrm{u}_{\mathrm{im}}\right\}, \mathrm{U}_{\mathrm{i}}$ ? $\mathrm{U}_{\mathrm{j}} j, \mathrm{i}^{1} \quad \mathrm{j}, \mathrm{i}, \mathrm{j}=1,2, \cdots, \mathrm{s}$.

$\left\{U_{i}\right\}$ is a part of the " $U$ ", $U_{i}$ is called a block.

\subsection{Evaluation set of evaluation object}

The evaluation set is a set of evaluation grades which are composed of the evaluation results of the evaluation objects ${ }^{[5]}$. The theory domain of set evaluation is $V=\left\{V_{1}, V_{2}, \cdots, V_{n}\right\}$. In the formula, $V_{j}$ represents the $j$-th evaluation result, $j=1,2, \cdots, n, \mathrm{n}$ is the total number of evaluation results, generally divided into 3 to 5 grades. For exam

$$
\mathrm{V}=\left\{\mathrm{V}_{1}, \mathrm{~V}_{2} \mathrm{~V},_{3} \mathrm{~V},{ }_{4} \mathrm{~V}\right\} \overline{\overline{5}}\left\{\begin{array}{l}
\text { Very satisfied, more satisfied, general, } \\
\text { not too satisfied, very not satisfied }
\end{array}\right\}
$$

\subsection{Calculation and evaluation for the weight vector of the evaluation index}

Weight is a numerical value which reflects the important degree of each index, and it is a very important parameter for fuzzy comprehensive evaluation, $A=\left(a_{1}, a_{2}, \cdots, a_{m}\right)$ is fuzzy vector of weight distribution. In the formula, $\mathrm{a}_{\mathrm{i}}$ indicates the weight of the $i$-th factor, and $\mathrm{a}_{\mathrm{i}}$ 振 0 , $\mathrm{a} \mathrm{a}_{\mathrm{i}}=1$.

In the current, there are methods to determine weight as follow: Experts estimate method, Delphi method, Characteristic value method, Weighted average method, and Analytic hierarchy process etc ${ }^{[6]}$. These methods are based on the following three reasons to implement: (a) the role of single index in the tender documents is different which reflect the objective aspect of each index; (b) the satisfaction degree of tendree is different which reflect the subjective attitude of the various indicators; (c) reliability degree of each index which reflect the reliability of index information.

3.4 Determine the fuzzy relationship matrix

After getting hierarchical fuzzy subsets, the each index $u_{i}$ of the evaluated object should be quantified, and then the judgment matrix $\mathrm{R}$ is established: 


$$
R=\left[\begin{array}{cccc}
r_{11} & r_{12} & \cdots & r_{1 n} \\
r_{21} & r_{22} & \cdots & r_{2 n} \\
\vdots & \vdots & \ddots & \vdots \\
r_{m 1} & r_{m 2} & \cdots & r_{m n}
\end{array}\right]
$$

In the formula, $r_{i j}$ indicates the membership of evaluated object existed from the index $u_{i}$ to hierarchical fuzzy subsets $v_{j}$. The performance of evaluated object in index $u_{i}$ is expressed by fuzzy vector between $r_{i}$ which called the single index evaluation matrix, the matrix is a fuzzy correlation index set $\mathrm{U}$ and comment sets $\mathrm{V}$ and can be considered as a potential relationship between influence factors and evaluated object.

Based on evaluation level, $r_{i j}$ is membership function which is marked to evaluated object by professionals and experts, the method transform abstract things into specific numerical then $r_{i j}$ can be obtained with the absolute value reduction method.

$$
r_{i j}=\left\{\begin{array}{c}
1,(i=j) \\
1-c \sum_{k=1}\left|x_{i k}-x j k\right|,(i \neq j) \quad 0 \# r_{i j} \quad 1, \mathrm{c} \text { is appropriate selected by assessment }
\end{array}\right.
$$

\subsection{Multi index fuzzy comprehensive evaluation}

Combined evaluation of the weight vector A with the fuzzy relation matrix R, the fuzzy comprehensive evaluation matrix B can be obtained:

$$
B=A ? R \quad\left(a_{1}, a_{2}, \cdots, a_{m}\right)\left[\begin{array}{cccc}
\eta_{1} & \eta_{2} & \cdots & \eta_{n} \\
r_{21} & \eta_{2} & \cdots & r_{2 n} \\
\vdots & \vdots & \ddots & \vdots \\
r_{m 1} & r_{m 2} & \cdots & r_{m n}
\end{array}\right]=\left(b_{1}, b_{2}, \cdots, b_{n}\right)
$$

Where, $b_{j}$ is the membership function of evaluation level fuzzy subset for evaluated object $v_{j}$.

$$
b_{j}=\underset{i=1}{m}\left(a_{i}, v_{i j}\right)=\max _{1 \leq i \leq m}\left\{a_{i}, r_{i j}\right\}, \quad j=1,2, \cdots, n
$$

\subsection{Final comprehensive evaluation results}

Fuzzy comprehensive evaluation is the process of calculating the membership function of evaluation level various fuzzy subset for evaluated object, it is usually a vector rather than a value. So we can use it to arrange and compare the evaluation index, then the comprehensive scores of each evaluation index is calculated and the best is selected by size. 
The rank is arranged in the corresponding order, so that it can be calculated by the mathematics method. In order to make each level can be in numerical processing, the each level is expressed as "1,2, $\cdots, \mathrm{m} "$, and then the corresponding component of B is summed to get relative position of evaluated object.

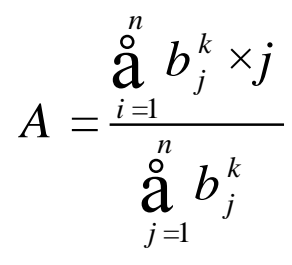

In the formula, $\mathrm{K}$ is a control factor in order to prevent the $b_{j}$ too large to influence the results.

\section{An example of using the fuzzy comprehensive evaluation method}

4.1 Establishment of evaluation index system and the determination of the weight 


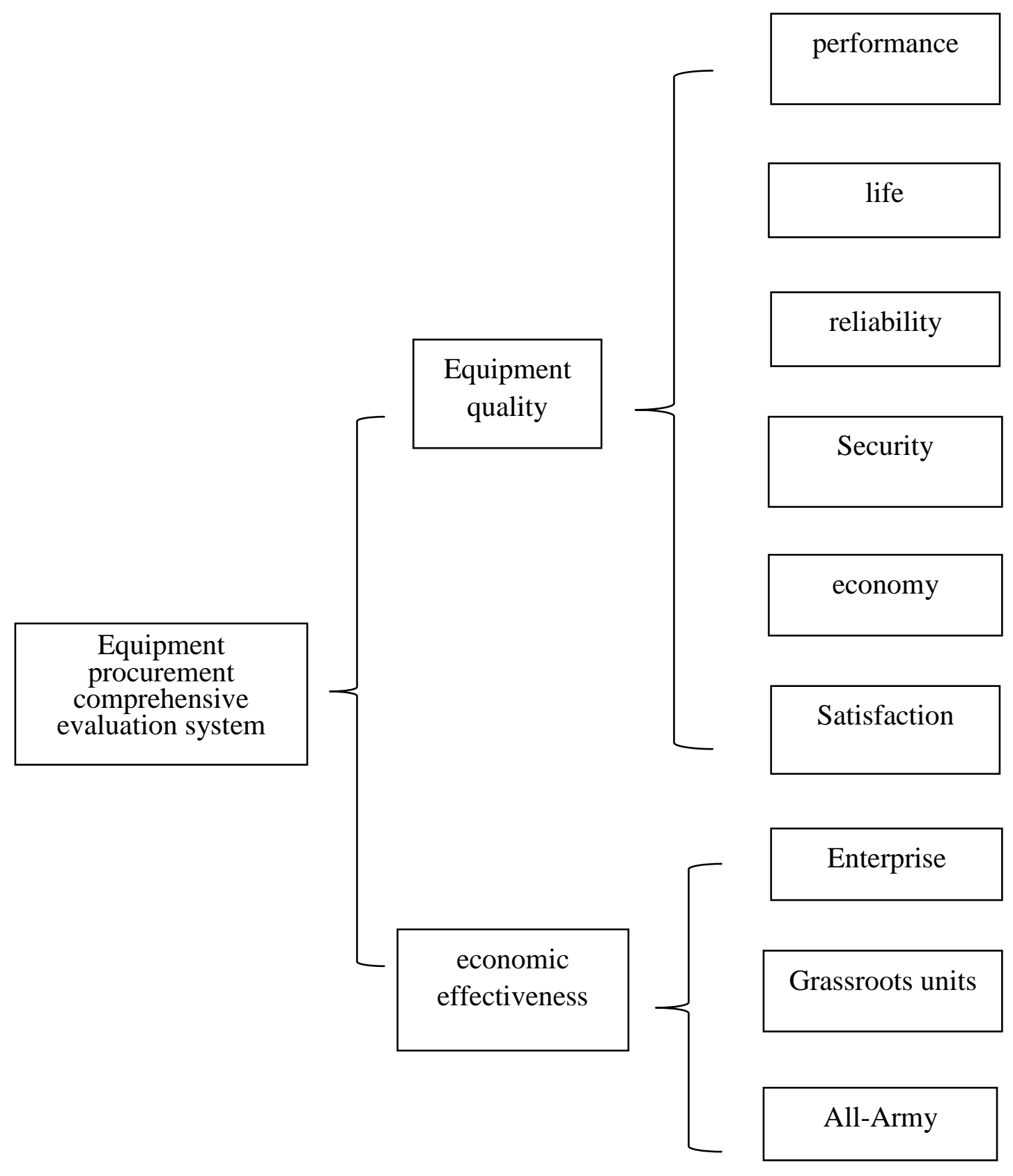

Table I

4.2 Determination of the evaluation set

$V=\left\{V_{1}, V_{2}, V_{3}, V_{4}, V_{5}\right\}=\left\{\begin{array}{l}\text { Very satisfied, more satisfied, general, } \\ \text { not too satisfied, very not satisfied }\end{array}\right\}$ 
4.3 Determination of fuzzy relationship matrix

The table is a statistical table for the evaluation of equipment procurement under the assumption:

\begin{tabular}{|c|c|c|c|c|c|}
\hline performance & Very satisfied & more satisfied & general & $\begin{array}{c}\text { not too } \\
\text { satisfied }\end{array}$ & $\begin{array}{c}\text { very not } \\
\text { satisfied }\end{array}$ \\
\hline life & 2 & 6 & 8 & 4 & 0 \\
\hline reliability & 1 & 2 & 10 & 7 & 1 \\
\hline Security & 3 & 5 & 12 & 2 & 0 \\
\hline economy & 0 & 8 & 6 & 3 & 0 \\
\hline Satisfaction & 0 & 3 & 9 & 6 & 0 \\
\hline Enterprise & 2 & 9 & 12 & 4 & 0 \\
\hline Grassroots units & 0 & 5 & 7 & 8 & 0 \\
\hline All-Army & 1 & 4 & 13 & 2 & 0 \\
\hline
\end{tabular}

Table II

4.4 Multi index fuzzy comprehensive evaluation

$\mathrm{B}=\mathrm{A} \cdot \mathrm{R}=(0.05,0.2725,0.47375,0.1925,0.01125)$

The result indicates that the tender benefit is not particularly good.

\section{Summary}

By fuzzy comprehensive evaluation method to Equipment competitive procurement bidding, the optimal bidder can be accurately selected, and the result is a vector rather than point values, so that the information is more abundant. The fuzzy evaluation object can be dealt with precise numbers rather than ambiguous text, and a reasonable and scientific quantitative evaluation to the fuzzy information can be quantitative evaluated.

In the actual using the shortcomings of the fuzzy comprehensive evaluation method is complex because of involving a variety of data processing and formula operation. When the factors set $U$ is relatively large and the sum of weighted vector is 1 , the relative subordinate degree of weight coefficient is usually smaller, then the weighted vector and fuzzy matrix R does not match, finally the calculated results will deviate from the true results and the resolution becomes worse, so that it was impossible to distinguish membership.

At present, the military implementation of the equipment competitive procurement face many difficulties, the study and continuous practice should be carried out to make the system more perfect.

\section{REFERENCES}

[1]Qiao Yu-ting. Research on industrial organization of weapon equipment competitive procurement [D], National University of Defense Technology, 2012.

[2]Sun Li-xin. A few thoughts the lowest bid [J], "Chinese engineering consulting", 2003. 
[3]Chen Li-xia. Discussion on the preparation of bidding documents for mechanical and electrical equipment [J], " China Science and Technology Expo " ,2012.

[4]Shan Hong-sheng. Study on equipment purchasing power for evaluation and evaluation and the related mechanism [D], North China Electric Power University, 2012.

[5]Wu Yao-bin ,Wang Ming-yu. Application of fuzzy comprehensive evaluation method in the quality evaluation of multimedia CAI courseware $[\mathrm{J}]$," Computer and information technology ", 2006.

[6]Huang Yi-rong. Fuzzy statistical method and its application [D], Jiangxi University o f Finance and Economics, 1995. 